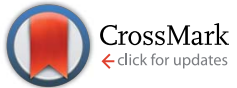

Cite this: RSC Adv., 2015, 5, 16101

Received 17th December 2014 Accepted 29th January 2015

DOI: $10.1039 / c 4 r a 16560 h$

www.rsc.org/advances

\title{
Important factors for effective use of carbon nanotube matrices in electrochemical capacitor hybrid electrodes without binding additives $\uparrow$
}

\author{
Ricardo Quintero, ${ }^{\text {ab }}$ Dong Young Kim, ${ }^{a}$ Kei Hasegawa, ${ }^{a}$ Yuki Yamada, ${ }^{\mathrm{b}}$ Atsuo Yamada \\ and Suguru Noda*a
}

\begin{abstract}
Various capacitive particles are currently available for use in electrochemical capacitors, but their electrical conductivities are typically low and require enhancement. Carbon nanotube (CNT) matrices can be used to fabricate self-supporting electrodes without binding or conducting additives. Herein, liquid dispersion and subsequent vacuum filtration were used to prepare thick $(\sim 100 \mu \mathrm{m})$ hybrid electrodes of activated carbon (AC) and CNTs. Factors including CNT type, AC particle size, solvent, and surfactant strongly affected the capacitance and rate performance of the hybrid electrodes. Different solvents and types of CNTs were best suited for pure CNT electrodes and AC-CNT hybrid electrodes; single-wall CNTs (SWCNTs) with a strong dispersant produced CNT electrodes with the best performance among pure CNT electrodes. Meanwhile, few-wall CNTs (FWCNTs) with a weak dispersant produced AC-CNT hybrid electrodes with the best performance among hybrid electrodes. Addition of $10 \mathrm{wt} \%$ FWCNTs to AC yielded a self-supporting hybrid electrode with improved performance $\left(132 \mathrm{~F} \mathrm{~g}^{-1}, 58 \mathrm{~F} \mathrm{~cm}^{-3}, 0.70 \mathrm{~F} \mathrm{~cm}{ }^{-2}\right.$ at $100 \mathrm{mV} \mathrm{s}^{-1}$ ) compared with that of a conventional $\mathrm{AC}$ electrode with conducting and binding additives $\left(74 \mathrm{~F} \mathrm{~g}^{-1}, 26 \mathrm{~F} \mathrm{~cm}^{-3}, 0.60 \mathrm{~F} \mathrm{~cm}^{-2}\right.$ at $\left.100 \mathrm{mV} \mathrm{s}^{-1}\right)$, and a pure electrode of expensive SWCNTs $\left(52 \mathrm{~F} \mathrm{~g}^{-1}\right.$, $26 \mathrm{~F} \mathrm{~cm}^{-3}, 0.26 \mathrm{~F} \mathrm{~cm}^{-2}$ at $100 \mathrm{mV} \mathrm{s}^{-1}$ ).
\end{abstract}

\section{Introduction}

Electrochemical capacitors (ECs), also known as supercapacitors, are receiving increasing attention as possible storage systems for electrical energy. Extensive research to improve the performance of ECs has been undertaken, including fabrication of active materials with higher energy densities, electrolytes with wider voltage windows and hybrid systems using Faradaic reactions. ${ }^{1}$ Activated carbon (AC) is the material of choice for electric double layer (EDL) capacitors because of its large capacitance, long cycling life, low cost and good processability. The high specific surface area (SSA) of 1000-3500 $\mathrm{m}^{2} \mathrm{~g}^{-1}$ (ref. 2) and the porous structure of AC allow charge storage at the electrode/electrolyte interface, with a capacitance of $10 \mu \mathrm{F} \mathrm{cm}^{-2}$ (ref. 3). Conventional electrodes are made from AC particles using conductive additives and polymeric binders that are chemically stable at given

${ }^{a}$ Department of Applied Chemistry, Waseda University, 3-4-1 Okubo, Shinjuku-ku, Tokyo, 169-8555, Japan. E-mail: noda@waseda.jp; Fax: +81 352862769; Tel: +81 352862769

${ }^{b}$ Department of Chemical System Engineering, The University of Tokyo, 7-3-1 Hongo, Bunkyo-ku, Tokyo 113-8656, Japan

$\dagger$ Electronic supplementary information (ESI) available: Elemental composition (wt\%) of pure FWCNT electrodes and AC2000-SWCNT (9:1) electrodes processed in $\mathrm{H}_{2} \mathrm{O}-\mathrm{SDBS}$, NMP and EtOH determined by XRF. See DOI: 10.1039/c4ra16560h electrochemical potentials. Other types of widely investigated capacitive particle are transition metal oxides, which can store considerable electrical charge through fast and reversible Faradaic redox reactions. Capacitances as high as $768 \mathrm{~F} \mathrm{~g}^{-1}$ for ruthenium oxide ${ }^{4}$ and $265-320 \mathrm{~F} \mathrm{~g}^{-1}$ for manganese oxide $\mathrm{e}^{5,6}$ have been achieved. However, some of these materials are limited by low surface area and electrical conductivity, making their efficient use difficult.

Carbon nanotubes (CNTs) possess high tensile strength, flexibility, electrical conductivity and reasonably high SSA. Pristine CNT electrodes exhibit excellent rate performance, i.e., a low capacitance reduction ratio at high scan rates, and moderate capacitances. ${ }^{7,8}$ Single-wall CNTs (SWCNTs) have the highest SSA for their exterior surface among CNTs, of up to $1320 \mathrm{~m}^{2} \mathrm{~g}^{-1}$. Pure SWCNT electrodes exhibit excellent rate performance, ${ }^{9}$ although their cost of up to $\sim 1000$ USD per $g$ limits their practical application. CNTs have also been used in electrodes as current-collecting substrates for other active materials such as conductive polymers and metal oxides, ${ }^{\mathbf{1 0 - 1 4}}$ and with high-voltage window electrolytes. ${ }^{15,16}$ However, the strong van der Waals interactions in SWCNTs ${ }^{17,18}$ leads to formation of bundles and disordered networks, which makes it difficult to realise their optimum mechanical and electronic properties. ${ }^{19,20}$

Chemical vapour deposition (CVD) is suitable for producing large amounts of CNTs. Fluidised-bed CVD (FB-CVD), in which 
catalyst-supported powders are uniformly heated and mixed with a reactant gas, is especially suitable to produce CNTs. Multi-wall CNTs (MWCNTs) are mass produced by FB-CVD at amounts of several hundred tons annually per plant and production cost of $\sim 100$ USD per kg. ${ }^{21}$ We previously developed FB-CVD, and realised the continuous and batch production of sub-millimetre-long few-wall CNTs (FWCNTs) ${ }^{22,23}$ and SWCNTs, ${ }^{24}$ respectively. FWCNTs offer advantages over SWCNTs in terms of cost, ease of manipulation, and capability of functionalization by oxidation while retaining conductivity. The flexibility and high aspect ratio of FWCNTs can yield selfsupporting films, and positive electrodes for lithium batteries have been developed using oxidised FWCNTs. ${ }^{25}$

Combining CNTs with AC in hybrid electrodes has been explored to increase the conductivity of conventional electrodes, and as a replacement for conventional conductive additives. ${ }^{26-29}$ Self-supporting hybrid films of AC and CNTs have been reported, ${ }^{30-32}$ which may produce light-weight, highcapacity electrodes without using metal collectors, thus avoiding their contribution to the weight of the device. ${ }^{33}$ In the current study, we use sub-millimetre-long FWCNTs $^{22,23}$ and SWCNTs $^{24}$ as matrix to hold capacitive particles for ECs. Pure CNT electrodes and AC-CNT hybrid electrodes are fabricated without binders, and their performance is compared with that of conventional hybrid electrodes of $\mathrm{AC}$ with the conductive additive acetylene black $(\mathrm{AB})$ and binder polytetrafluoroethylene (PTFE) (Fig. 1a). A photo of a typical AC-CNT hybrid film (Fig. 1b) shows its self-supporting and flexible nature without the aid of binders. Both conventional and proposed electrodes had a layered structure parallel to the film surface (Fig. 1c and d). In the latter electrode (Fig. 1d), AC particles distributed uniformly and individual AC particles were covered well with numerous CNTs. When we consider practical devices, volumetric and areal capacitances are very important in addition to gravimetric capacitances. Thus we worked on thick electrodes $(\sim 200 \mu \mathrm{m}$ as-prepared and $\sim 100 \mu \mathrm{m}$ after pressing) and discussed these capacitance values. The effects of factors including the types of solvent and surfactant used to disperse AC and CNTs, AC particle size, SSA of AC, and CNT loading on electrode performance are investigated systematically to achieve hybrid EC electrodes with enhanced capacity and conductivity.

\section{Experimental}

\section{Electrode preparation}

FWCNTs and SWCNTs were fabricated by FB-CVD using $\mathrm{C}_{2} \mathrm{H}_{2}$ as a carbon source as reported previously. ${ }^{22-24}$ The CNTs were highly pure as produced ( $99 \mathrm{wt} \%$ or higher), so we used them without any purification. To prepare pure CNT electrodes, SWCNTs and FWCNTs were dispersed in three different solvents: $\mathrm{H}_{2} \mathrm{O}$ with sodium dodecylbenzenesulphonate (SDBS) surfactant (0.5 wt\%), $N$-methylpyrrolidone (NMP) and ethanol (EtOH). Dispersion was carried out using a bath-type 600-W sonicator for $30 \mathrm{~min}$, with a cooling unit to maintain the temperature at $20{ }^{\circ} \mathrm{C}$. Electrodes were formed by vacuum filtration of the dispersions through PTFE membrane filters with a pore size of $5 \mu \mathrm{m}$. To remove residual SDBS, electrodes were rinsed with boiling distilled water, soaked for $10 \mathrm{~min}$ in $60 \mathrm{wt} \% \mathrm{HNO}_{3}$ at room temperature, and finally rinsed with boiling distilled water. Residual EtOH and NMP were removed by drying the electrodes at 150 and $205{ }^{\circ} \mathrm{C}$, respectively.
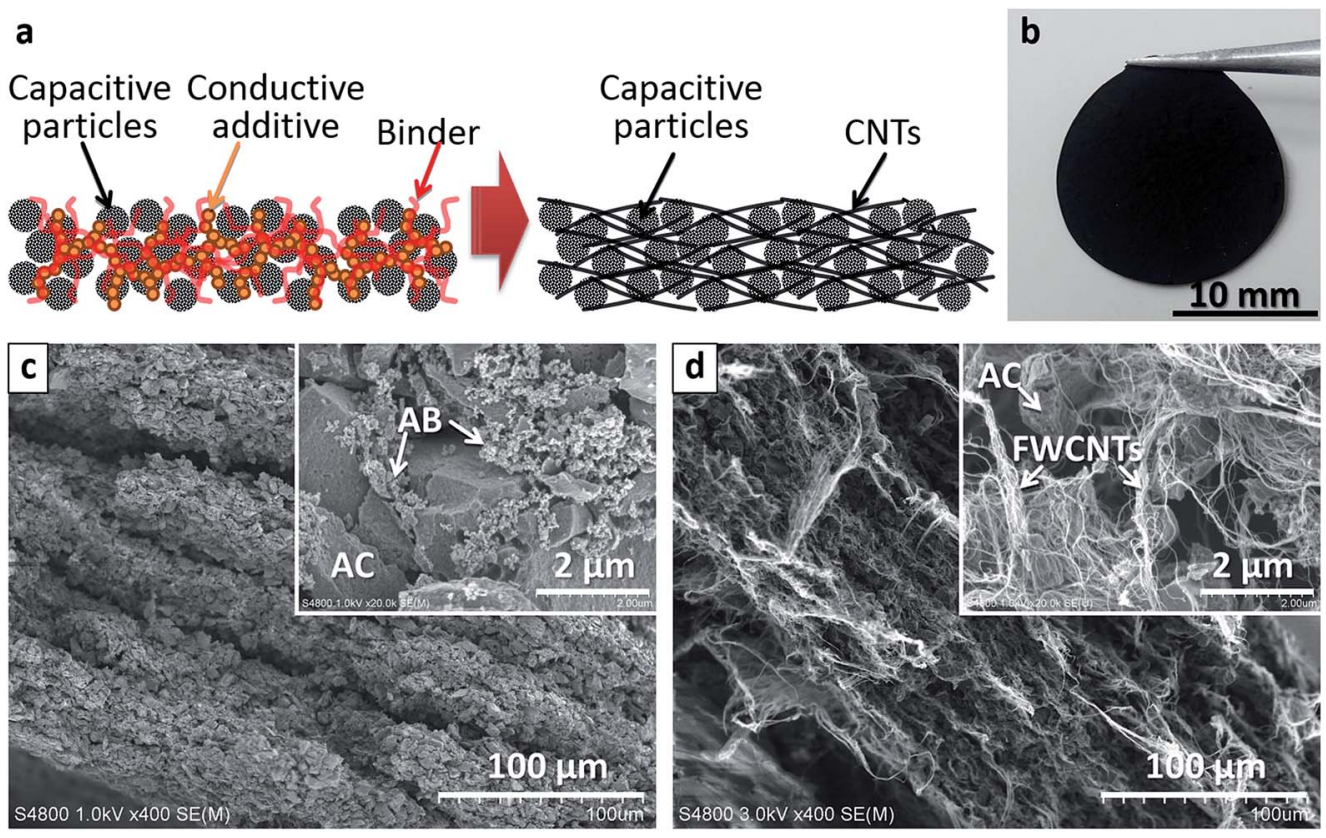

Fig. 1 (a) Schematic diagrams of conventional and proposed electrode configurations using AC particles and CNTs. (b) Photograph of a selfsupporting AC-CNT hybrid film. Scanning electron microscope (SEM) images of a (c) conventional AC electrode using AB and PTFE and (d) AC-FWCNT hybrid electrode. 
To prepare AC-CNT hybrid electrodes, different amounts of CNTs were mixed with AC particles in different solvents. Two different types of AC were used: activated charcoal untreated powder (100-400 mesh, $1001 \mathrm{~m}^{2} \mathrm{~g}^{-1}$, Sigma-Aldrich, St. Louis, MO, USA) and YP80-F AC (5-20 $\mu \mathrm{m}$ diameter, $2042 \mathrm{~m}^{2} \mathrm{~g}^{-1}$, Kuraray Chemical Co., Tokyo, Japan), which are referred to as AC1000 and AC2000, respectively. Different ratios of AC and CNTs were added to the dispersing agents $\mathrm{H}_{2} \mathrm{O}-\mathrm{SDBS}(0.5 \mathrm{wt} \%)$, $\mathrm{NMP}$ and EtOH to give mixtures with $0.1 \mathrm{mg}$ of carbon material per $\mathrm{mL}$ of solution. Dispersion of each mixture was carried out using a bath-type $600-\mathrm{W}$ sonicator for $30 \mathrm{~min}$ at $20{ }^{\circ} \mathrm{C}$. Electrodes were obtained by vacuum filtration of the dispersions through PTFE membrane filters with a pore size of $5 \mu \mathrm{m}$ and subsequent drying at $150{ }^{\circ} \mathrm{C}$ in air for $\sim 3 \mathrm{~h}$. Residual SDBS, EtOH, and NMP were removed in the same manner as for the pure CNT electrodes. Most electrodes were $\sim 200 \mu \mathrm{m}$ thick as prepared and $\sim 100 \mu \mathrm{m}$ thick after pressing at $10 \mathrm{MPa}$.

To observe the dispersion states of CNTs in different dispersants, the dispersions were spin-coated at $4000 \mathrm{rpm}$ for $30 \mathrm{~s}$ on $\mathrm{Si}$ wafers that had been pretreated in piranha solution (96 wt\% sulphuric acid and $30 \mathrm{wt} \%$ hydrogen peroxide with a volume ratio of $70: 30$ ) for $10 \mathrm{~min}$.

\section{Electrode characterization}

Microstructures of the CNT-based self-supporting films were analysed by scanning electron microscopy (SEM, Hitachi S-4800, Tokyo, Japan). The CNTs spin-coated on Si wafers were also analysed by SEM to evaluate their dispersion state. Sheet resistance was determined by the four-point probe method. SSAs were calculated by Brunauer-Emmett-Teller (BET) analysis of nitrogen adsorption isotherms measured at $77 \mathrm{~K}$ (BEL Japan Belsorp-28SA, Osaka, Japan or Quantachrome Instruments Autosorb 1C, Boynton Beach, FL, USA). Elemental composition was determined using a wavelength-dispersive X-ray fluorescence spectrometer (XRF, Rigaku ZSX Primus II, Akishima, Japan).

Three-electrode cells were used to perform cyclic voltammetry (CV), electrochemical impedance spectroscopy (EIS) and galvanostatic charge-discharge measurements with a potentiostat (Bio-Logic VMP3, France). The three-electrode cell consisted of either a pure CNT or AC-CNT film (sandwiched with two Ti meshes and pressed at $10 \mathrm{MPa}$ ) as the working electrode, Pt-mesh counter electrode and $\mathrm{Ag} / \mathrm{AgCl}$ reference electrode (in saturated aqueous $\mathrm{NaCl}$ ). The electrolyte was aqueous $1 \mathrm{M}$ $\mathrm{H}_{2} \mathrm{SO}_{4}$. EIS was performed over the frequency range of $100 \mathrm{kHz}$ to $10 \mathrm{mHz}$ at a constant potential of $0.0 \mathrm{~V} v \mathrm{~s}$. $\mathrm{Ag} / \mathrm{AgCl}$, and the amplitude of the excitation signal was $\pm 10 \mathrm{mV}$.

\section{Results and discussion}

\section{Performance of pure SWCNT and FWCNT electrodes}

The dispersibility and cost of CNTs are important considerations in their practical application, so the properties of different types of CNTs are compared in this section. The CVs in Fig. 2 provide information about the rate capability of the SWCNT and FWCNT electrodes, and the influence of different
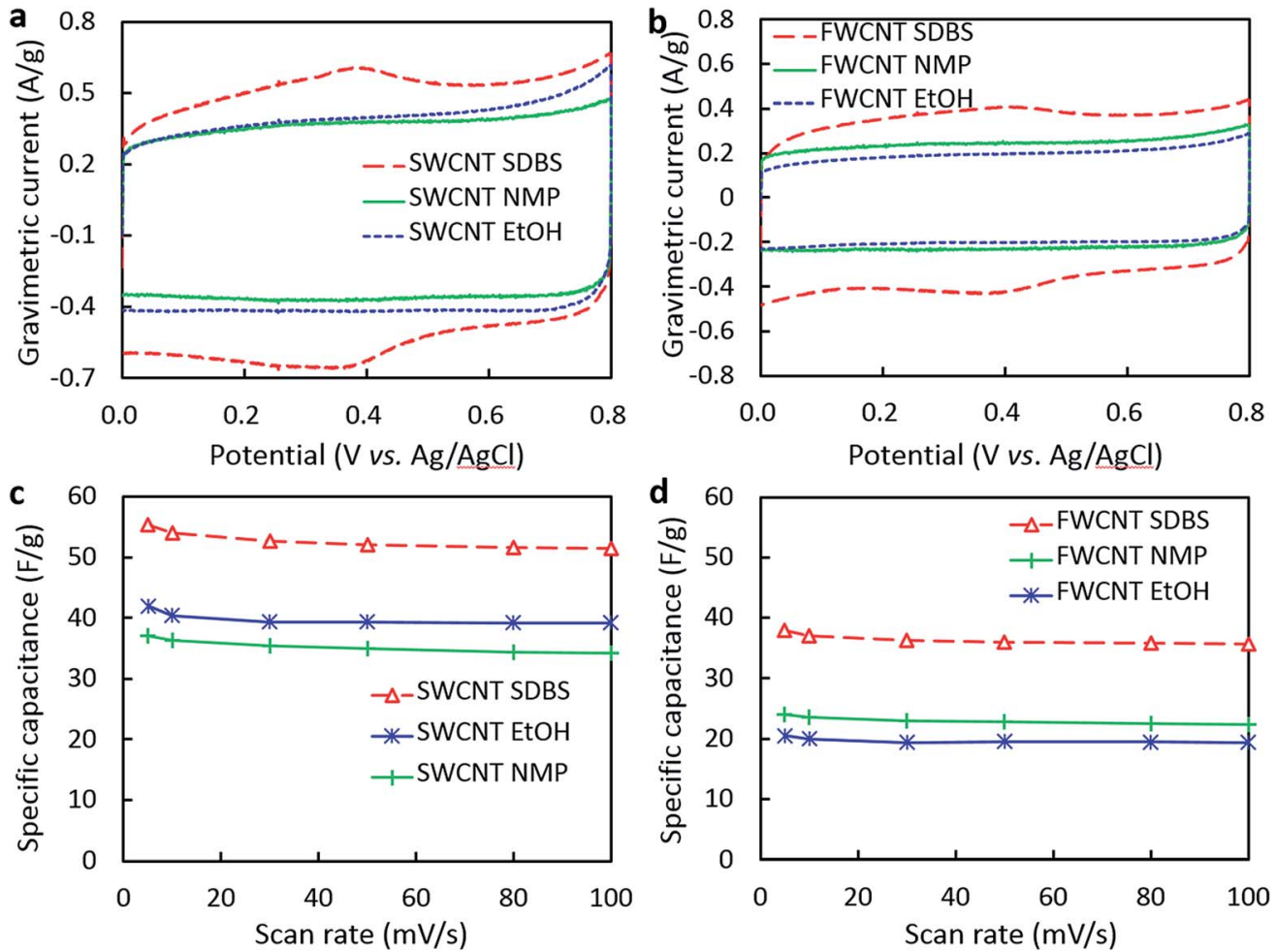

Fig. 2 ( $a$ and b) CVs of pure SWCNT and FWCNT electrodes processed in $\mathrm{H}_{2} \mathrm{O}-\mathrm{SDBS}$, NMP and EtOH (scan rate $=10 \mathrm{mV} \mathrm{s}{ }^{-1}$ ). (c and d) Dependence of the specific capacitance of the pure SWCNT and FWCNT electrodes processed using different solvents on scan rate at 0-0.8 V. 
dispersion solvents. The gravimetric current of the pure SWCNT electrodes (Fig. 2a and c) was higher than that of the pure FWCNT ones (Fig. 2b and d), but the shapes of the CVs (Fig. 2a and b) were similar for the electrodes prepared from dispersions of the same solvents. The CVs of the electrodes processed in NMP and EtOH exhibited regular rectangular shapes without any apparent peaks (Fig. 2a and b), similar to those of an ideal capacitor, where electric charge $(q)$ is proportional to applied voltage $(V)$, and the constant of proportionality is capacitance $(C)$; that is, $q=C V$. High electrical conductivity and the absence of parasitic reactions translate into rectangular CVs, which indicate uniform ion diffusion and good rate performance. ${ }^{34}$ The electrodes processed in $\mathrm{H}_{2} \mathrm{O}$-SDBS exhibited a broad peak at around $0.4 \mathrm{~V}$ in the forward and reverse scans (Fig. 2a and b), consistent with a contribution from pseudocapacitance in addition to the predominant EDL capacitance. This peak may result from the acid rinsing of the electrode to remove SDBS. The immersion time of the electrode in acid was sufficient to form oxygen functionalities like $-\mathrm{COOH},-\mathrm{OH}$, and $>\mathrm{C}=\mathrm{O}$ on the CNT surface. ${ }^{8,35}$ The electrode processed in $\mathrm{H}_{2} \mathrm{O}-\mathrm{SDBS}$ solution had a higher oxygen content (4.17 wt\%) than those of the electrodes processed in NMP (2.03 wt\%) and EtOH (1.47 wt\%) (see ESI, Table S1†), confirming that rinsing with acid resulted in the presence of additional functional groups. Thus soaking in $\mathrm{HNO}_{3}$ had two different effects: removing SDBS to increase the conductivity and the surface area available for EDL capacitance of the CNT networks, and modifying the carbon surface with electrochemically active oxygen-containing groups. The contributions from specific functionalities on carbon surfaces to capacitance has been widely reported, including those from $\mathrm{N}$ - and $\mathrm{S}$-based groups, ${ }^{36-41}$ although $\mathrm{N}$ and $\mathrm{S}$ contents were low in our samples.

$C$ of the electrodes was calculated from the CVs using the expression:

$$
C=\frac{1}{v} \frac{\int_{E_{1}}^{E_{2}} I(E) \mathrm{d} E}{E_{2}-E_{1}},
$$

where $v$ is scan rate, $E$ is voltage and $I$ is current. Specific capacitance was calculated by dividing $C$ by the mass of CNTs for pure CNT electrodes, and the mass of CNTs and AC for hybrid electrodes. Specific capacitances were independent of the scan rate, even at $100 \mathrm{mV} \mathrm{s}^{-1}$ (Fig. $2 \mathrm{c}$ and $\mathrm{d}$ ), revealing the good rate capability of these electrodes. The maximum capacitance for each electrode depended on dispersion solvent, and was highest for the electrodes processed in $\mathrm{H}_{2} \mathrm{O}-\mathrm{SDBS}$ ( 55 and $52 \mathrm{~F} \mathrm{~g}^{-1}$ at 5 and $100 \mathrm{mV} \mathrm{s}^{-1}$ for SWCNT electrodes, respectively; 38 and $36 \mathrm{~F} \mathrm{~g}^{-1}$ at 5 and $100 \mathrm{mV} \mathrm{s}^{-1}$ for FWCNT electrodes, respectively). The better performance of the electrodes processed in $\mathrm{H}_{2} \mathrm{O}$-SDBS possibly resulted from their better dispersion in this solvent than in NMP and $\mathrm{EtOH}$, which led to the formation of an electrically conductive network with higher electrolyte-accessible surface area, in addition to the abovementioned pseudocapacitance contribution.
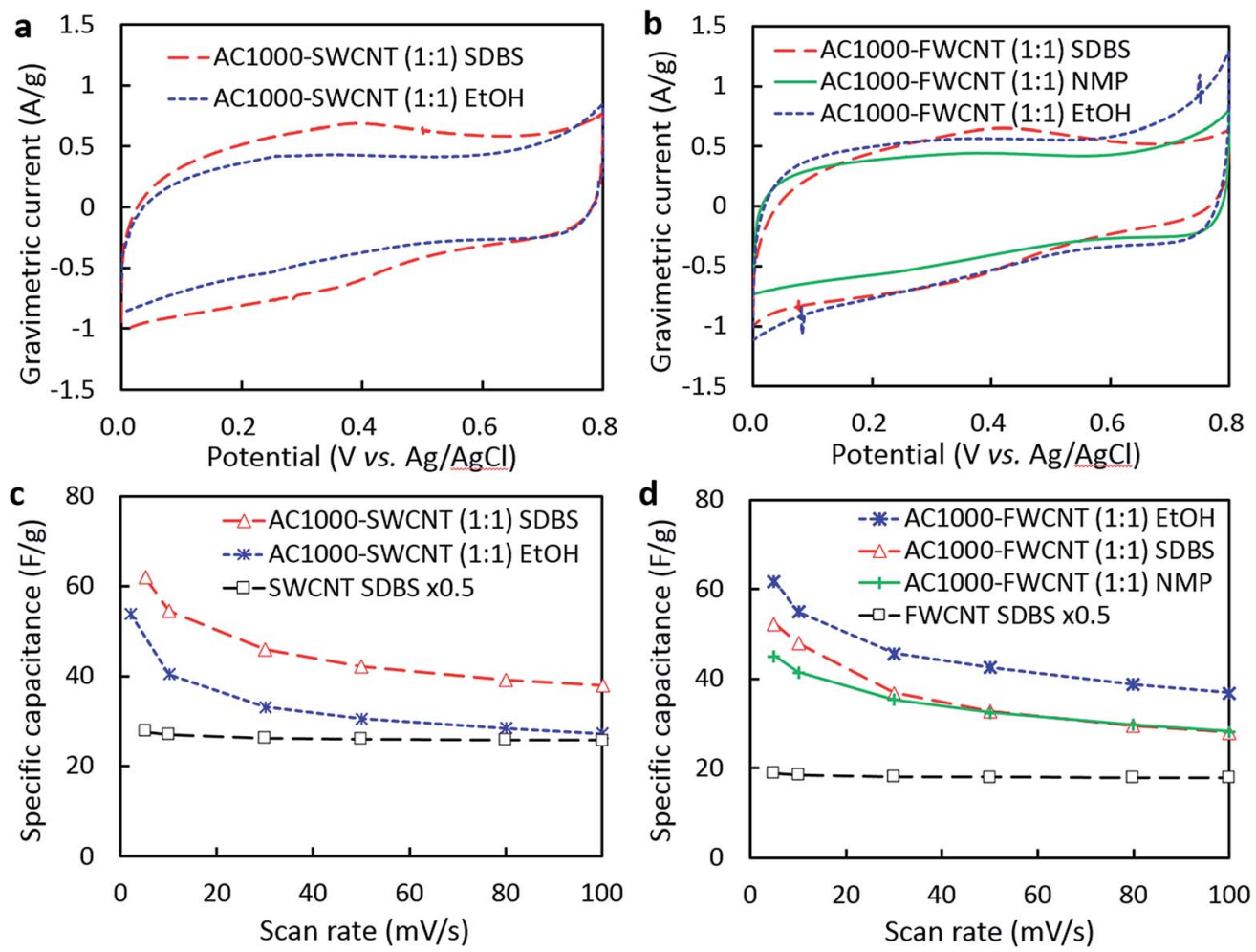

Fig. 3 (a and b) CVs of AC1000-SWCNT (1:1) and AC1000-FWCNT (1:1) electrodes processed in $\mathrm{H}_{2} \mathrm{O}-\mathrm{SDBS}, \mathrm{NMP}$ and EtOH (scan rate $=$ $10 \mathrm{mV} \mathrm{s}^{-1}$ ). (c and d) Dependence of capacitance on scan rate of the hybrid electrodes. Plots for pure CNT electrodes (from Fig. $2 \mathrm{c}$ and d) are also shown for comparison. Specific capacitance values shown for pure CNT electrodes have been halved to clarify the contribution from AC in the hybrid electrodes. 


\section{Effect of dispersant on the performance of AC-SWCNT and} AC-FWCNT hybrid electrodes

Next, equal weights of AC1000 and CNTs were used to prepare hybrid electrodes to examine the effect of dispersant on the performance of AC-CNT hybrid electrodes. The CVs of the hybrid electrodes processed in EtOH and NMP exhibited a rectangular shape (Fig. 3a and b). The electrodes processed in $\mathrm{H}_{2} \mathrm{O}$-SDBS had non-rectangular CVs with a broad peak centred at $0.4 \mathrm{~V}$ resulting from the contribution of redox reactions consistent with oxidation of the carbon surface during rinsing with $\mathrm{HNO}_{3}{ }^{8}$

The rate capability plots in Fig. $3 \mathrm{c}$ and d provide insight into the effect of each dispersant on the porous structure of the hybrid electrodes. The AC-SWCNT electrode processed in $\mathrm{H}_{2} \mathrm{O}$-SDBS had higher specific capacitance than that processed in EtOH (Fig. 3c). In particular, the specific capacitance of the latter approached that of the pure SWCNT electrode containing the same weight of CNTs, showing the diminishing contribution of AC to specific capacitance at high scan rates. It is probable that SWCNTs were not effectively dispersed in EtOH, resulting in poor electrical contact with AC particles. Interestingly, the opposite result was obtained for AC-FWCNT electrodes; the electrode processed in EtOH exhibited the highest specific capacitance while that processed in $\mathrm{H}_{2} \mathrm{O}-\mathrm{SDBS}$ did the lowest one among the AC1000-FWCNT electrodes. All of the electrodes exhibited higher specific capacitances than that of the pure FWCNT electrode containing the same weight of CNTs at high scan rates, suggesting sufficient electrical contact with AC particles. However, the specific capacitance of the AC-FWCNT electrodes was higher for those processed in EtOH than the other solvents, suggesting that SDBS and NMP were adsorbed in the pores of AC, which decreases the electrolyteaccessible area of AC. From a practical aspect, it is

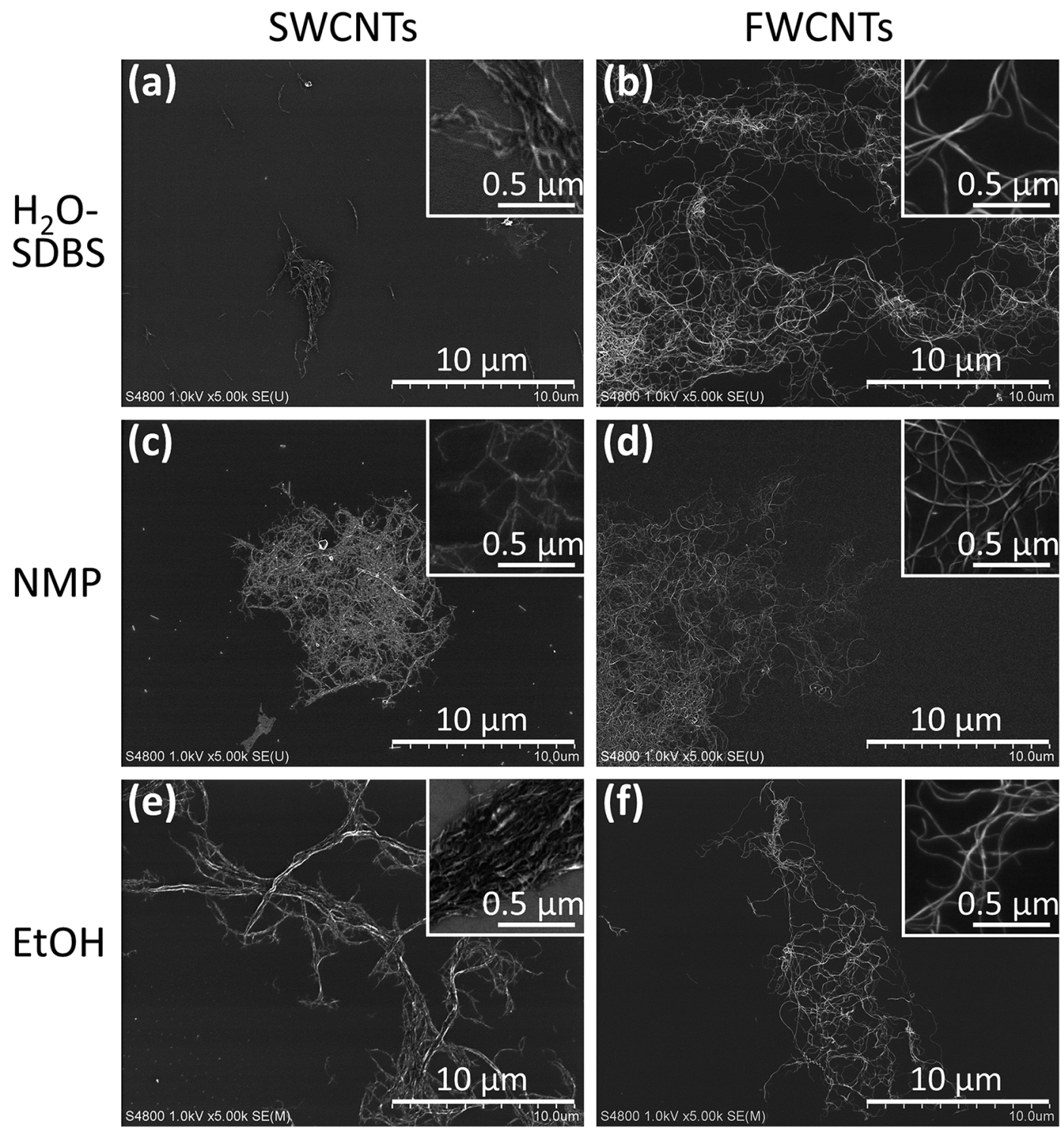

Fig. 4 SEM images of dispersions of ( $a, c$ and e) SWCNTs and ( $b$, $d$ and f) FWCNTs in ( $a$ and b) $\mathrm{H}_{2} \mathrm{O}-\mathrm{SDBS}$, (c and d) NMP, and (e and f) EtOH spincoated on Si wafers. 
Table 1 Specific surface area (SSA) and bulk conductivity $(\sigma)$ of AC1000, FWCNT, and AC1000-FWCNT electrodes processed in $\mathrm{H}_{2} \mathrm{O}-\mathrm{SDBS}$ and $\mathrm{EtOH}$

\begin{tabular}{llccc}
\hline & & AC1000-FWCNT & AC1000-FWCNT \\
& AC1000 & FWCNT (EtOH) & $(1: 1)\left(\mathrm{H}_{2} \mathrm{O}-\mathrm{SDBS}\right)$ & \\
\hline $\mathrm{SSA}\left(\mathrm{m}^{2} \mathrm{~g}^{-1}\right)$ & 1001 & 428 & 357 & 528 \\
$\sigma\left(\mathrm{S} \mathrm{cm}^{-1}\right)$ & N.A. & 85.7 & 48.8 & 36.6
\end{tabular}

encouraging that similar specific capacitance and rate performance were achieved for the AC-FWCNT electrode processed in EtOH to those of the AC-SWCNT electrode processed in $\mathrm{H}_{2} \mathrm{O}$-SDBS. However, the factors affecting the enhancement of specific capacitance by hybridization with AC should be different for these two electrodes, so next we examined the dispersibility of CNTs and adsorption of dispersants in AC pores.

The dispersion states of CNTs in different solvents were examined by spin-coating the dispersions on $\mathrm{Si}$ wafers and observing them by SEM (Fig. 4). The low-magnification images show the aggregate structure while the inset high-magnification images show the bundle structure of the CNTs. These SEM images reveal differences in the dispersion states of SWCNTs and FWCNTs. SWCNTs formed small $(\sim 5 \mu \mathrm{m})$, medium $(\sim 10 \mu \mathrm{m})$, and large $(\gg 10 \mu \mathrm{m})$ aggregates in $\mathrm{H}_{2} \mathrm{O}$-SDBS, NMP, and EtOH, respectively. In particular, EtOH-processed SWCNTs formed thick bundles composed of many SWCNTs (inset of Fig. 4e), confirming their poor dispersibility in EtOH. In contrast, FWCNTs adopted a similar dispersion state of large aggregates $(>10 \mu \mathrm{m})$ of thin bundles regardless of solvent, revealing their good dispersibility. These images confirm that mild dispersants, which do not obstruct the pores of AC, can be used for FWCNTs.

The electrical conductivity and SSA of electrodes processed in $\mathrm{H}_{2} \mathrm{O}$-SDBS and EtOH are presented in Table 1. SDBS appeared to be adsorbed within the pores of AC1000, even after successive rinsing with boiling water and $\mathrm{HNO}_{3}$. This decreased the available surface area of the AC1000-FWCNT electrode to $357 \mathrm{~m}^{2} \mathrm{~g}^{-1}$, compared with $528 \mathrm{~m}^{2} \mathrm{~g}^{-1}$ for the electrode processed in EtOH. The SSA for the electrode processed in EtOH is still smaller than the expected value of $715 \mathrm{~m}^{2} \mathrm{~g}^{-1}$ for a simple AC1000-FWCNT mixture, so EtOH reduces the available surface of AC to some extent. A higher bulk conductivity $(\sigma)$ of $48.8 \mathrm{~S} \mathrm{~cm}^{-1}$ was achieved using electrodes processed in $\mathrm{H}_{2} \mathrm{O}$-SDBS than in EtOH. This was because of the better dispersion and network formation of CNTs in $\mathrm{H}_{2} \mathrm{O}-\mathrm{SDBS}$ than in EtOH, and the effective CNT doping that occurred during acid rinsing. EtOH can disperse both AC and FWCNTs to a certain extent, with $\sigma=36.6 \mathrm{~S} \mathrm{~cm}^{-1}$ for the AC1000-FWCNT electrode processed in EtOH. The effect of dispersant on the available surface area of capacitive particles is an important consideration when aiming to maximise charge storage. Different results were obtained for the pure CNT and hybrid AC-CNT electrodes. SWCNTs exhibited better performance in pure CNT electrodes than FWCNTs because of their higher conductivity and SSA. Conversely, FWCNTs yielded better performance than SWCNTs when hybridised with AC because of their good dispersibility in EtOH, which did not obstruct the pores in AC too much. Thus, EtOH and FWCNTs were used in the following study of AC-CNT hybrid electrodes.

\section{Effect of AC particle size on electrochemical capacitance}

To obtain different particle sizes of capacitive AC, AC1000 was ultrasonically treated in EtOH in a bath-type ultrasonicator for $16 \mathrm{~h}$. The resulting material is referred to as US AC1000. The cavitation energy during ultrasonication can disperse and fracture solids, ${ }^{42}$ and an overall reduction in AC particle size from $20-100$ to $10-60 \mu \mathrm{m}$ was observed following ultrasonic treatment (Fig. 5).
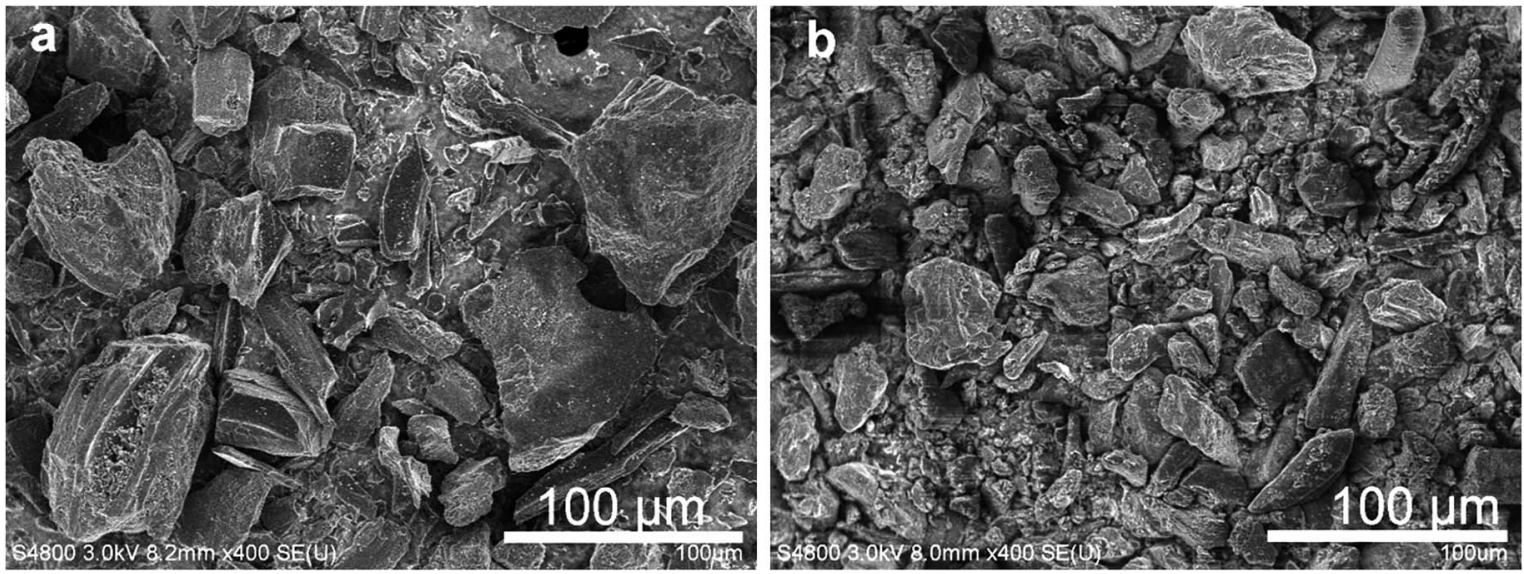

Fig. 5 SEM images of (a) as-received AC1000 and (b) AC1000 after ultrasonication for 16 h (US AC1000). 

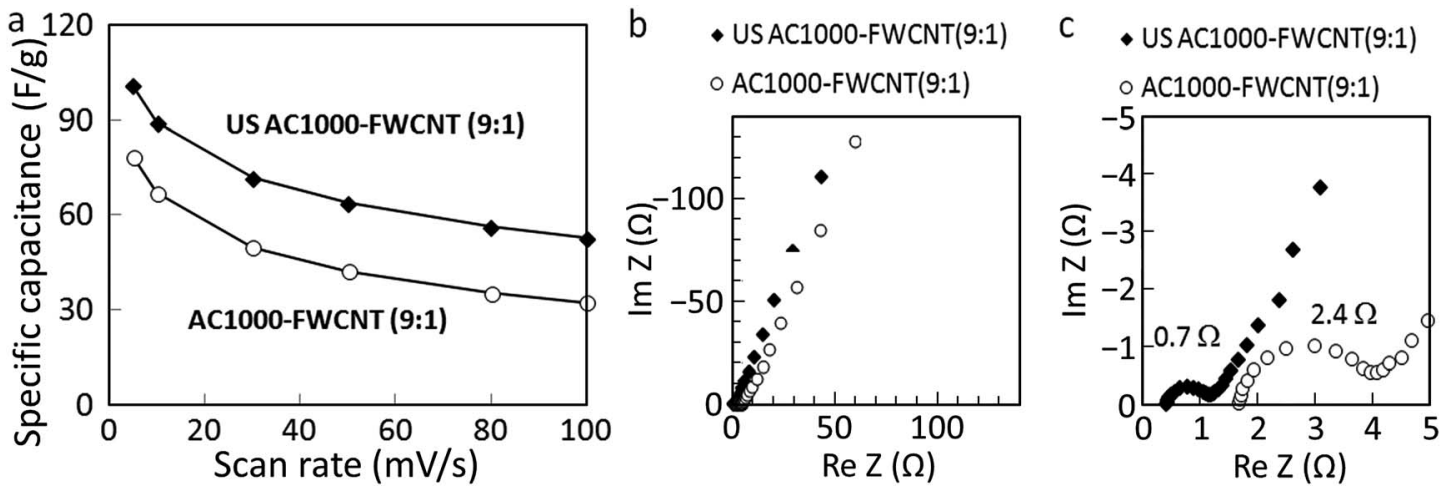

Fig. 6 Effect of AC particle size on the electrochemical performance of AC-FWCNT hybrid electrodes. (a) Rate performance determined from CVs of AC1000-FWCNT $(9: 1)$ and US AC1000-FWCNT $(9: 1)$ electrodes. Nyquist plots of the same electrodes for the (b) entire range and (c) high-frequency range.

The FWCNT loading of the electrode was reduced to increase the amount of capacitive AC to $90 \mathrm{wt} \%$. The electrical conductivities of the corresponding AC1000-FWCNT and US AC1000-FWCNT electrodes were 5.17 and $8.73 \mathrm{~S} \mathrm{~cm}^{-1}$, respectively, suggesting less disturbance of the electrical conduction pathway by smaller US AC1000 particles than by larger ones. The rate performance of both hybrid electrodes is illustrated in Fig. 6a. An increase in the specific capacitance of $22-39 \%$, and improvement in rate performance were observed for the hybrid electrodes with smaller particles, i.e., US AC1000 compared with those of the electrodes with larger ones.

EIS measurements were carried out to further analyse the resistance of the hybrid electrodes using Nyquist plots, which are depicted in Fig. $6 \mathrm{~b}$ and c. Information about electrolyte, contact and ion-diffusion resistances can be obtained from these plots. In general, a straight line along the imaginary axis is related to ideal EDL capacitance, and in real capacitors with a series resistance, this line has a finite slope, representing the diffusive resistivity of the electrolyte within the pores of the electrode. ${ }^{43}$ The US AC1000-FWCNT electrode exhibited a lower equivalent series resistance (ESR) than the AC1000-FWCNT one. Zhang et al $^{44}$ evaluated the effect of particle size of AC with a high surface area on electrode performance using conventional
EC electrode architecture. They obtained higher rate performance for smaller AC particles mainly due to the low intraparticle resistivity and rapid diffusion of ions within pores of AC particles. Although the solution series resistance and polarization resistance cannot be reduced by the AC particle size, the use of smaller AC particles is also effective at enhancing the rate performance of our AC-FWCNT hybrid electrodes.

\section{Effect of SSA and particle size of AC on electrode performance}

AC1000 and AC2000 particles were used to determine the effects of the particle size and SSA of capacitive particles on the performance of hybrid electrodes. As-received AC2000 had a much smaller average particle size of 10-15 $\mu \mathrm{m}$ than that of asreceived AC1000 $(20-100 \mu \mathrm{m})$. The SEM images in Fig. 7 show the morphologies of the prepared electrodes, in which the size and shape of the AC particles can be distinguished. The mechanically robust matrix of compact interwoven FWCNTs bound to the AC particles, with their surface being partially or completely covered by the flexible FWCNTs.

The SSA and conductivity for the AC-FWCNT $(9: 1)$ hybrid films are summarised in Table 2. BET analyses indicated that the SSA of AC2000 was twice that of AC1000, and almost five
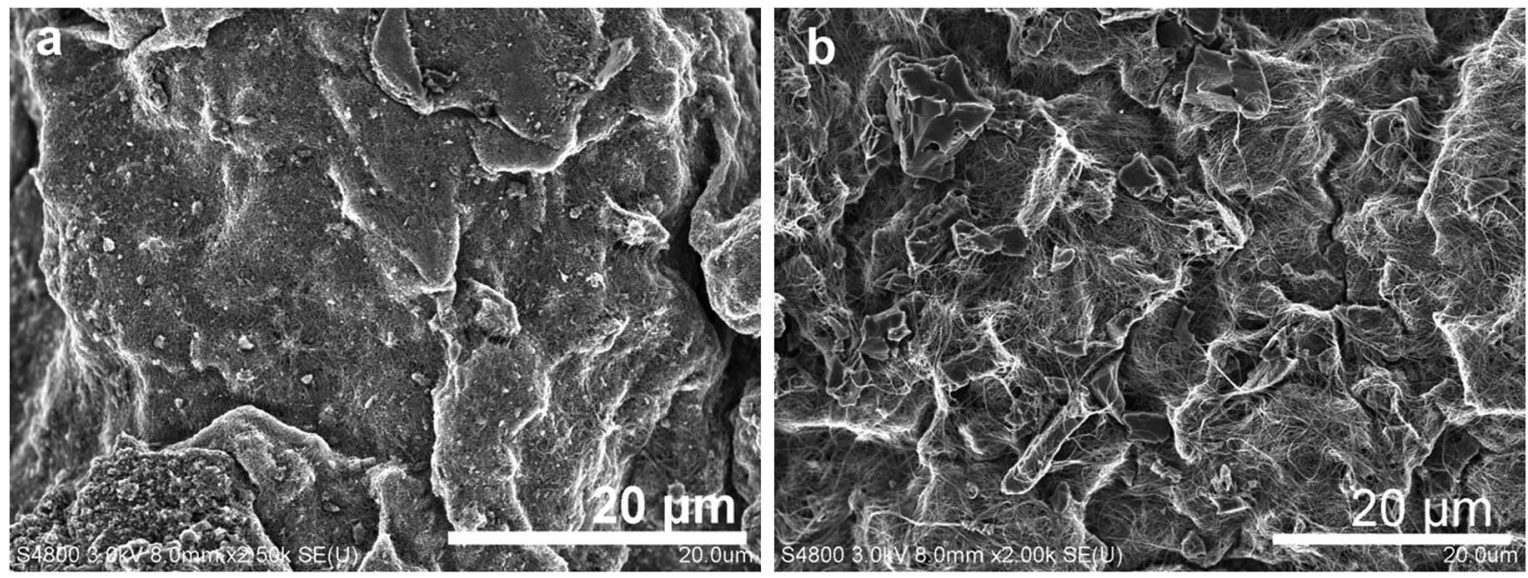

Fig. 7 SEM images of the (a) AC1000-FWCNT (9:1) and (b) AC2000-FWCNT (9: 1) electrodes. 
Table 2 Specific surface area (SSA) and bulk conductivity $(\sigma)$ of FWCNT and AC-FWCNT electrodes

\begin{tabular}{llccc}
\hline & AC2000 & FWCNT (EtOH) & $\begin{array}{l}\text { AC1000-FWCNT } \\
(9: 1)(\text { EtOH })\end{array}$ & $\begin{array}{l}\text { AC2000-FWCNT } \\
(9: 1)(\text { EtOH })\end{array}$ \\
\hline SSA $\left(\mathrm{m}^{2} \mathrm{~g}^{-1}\right)$ & 2042 & 428 & 857 & 1783 \\
$\sigma\left(\mathrm{S} \mathrm{cm}^{-1}\right)$ & N.A. & 85.7 & 5.17 & 10.1 \\
& & & &
\end{tabular}

times that of FWCNTs (Table 2). The BET SSAs of the AC-FWCNT hybrids included the individual contributions of both AC and CNTs. Although the SSA of AC2000-FWCNT of $1783 \mathrm{~m}^{2} \mathrm{~g}^{-1}$ is slightly smaller than the simple sum of the SSAs of AC2000 (0.9 g) and FWCNT (0.1 g) of $1881 \mathrm{~m}^{2} \mathrm{~g}^{-1}$, EtOH only reduced the available surface by small amount as expected. The conductivity of the AC2000-FWCNT electrode was $10.1 \mathrm{~S} \mathrm{~cm}^{-1}$, higher than that of the AC1000-FWCNT electrode of $5.17 \mathrm{~S} \mathrm{~cm}^{-1}$. The smaller AC2000 particles disturbed electrical conduction less than the larger AC1000 particles, in a similar manner to the small US AC1000 particles.

The CVs of the AC1000-FWCNT (9:1) and AC2000-FWCNT $(9: 1)$ electrodes in Fig. 8 show the change in electrical current of the electrodes at different potentials. These voltammograms suggest that there are important differences in the capacitance mechanisms and rate performances of these electrodes. The AC1000-FWCNT electrode exhibited no visible peaks, and its CVs were irregular, especially in the last scan segments (0.0-0.1 V and 0.7-0.8 V). The AC2000-FWCNT electrode exhibited broad peaks centred at 0.4 and $0.2 \mathrm{~V}$ in the forward and reverse scans, respectively, in addition to the overall rectangular shape. These peaks were consistent with fast redox reactions of functional groups, although we did not treat the AC2000-FWCNT hybrid with nitric acid in this experiment. The source of these redox peaks may be the evolution of activated oxygen species adsorbed on the carbon electrode surface, and the subsequent formation of quinoidal species, ${ }^{45}$ although further investigation is needed to clarify their origin. Elemental characterization of AC2000-FWCNT electrodes prepared using different dispersants is shown in Table $\mathrm{S} 2 \uparrow$ for reference.

The specific capacitances of the electrodes containing the two types of AC at different scan rates are shown in Fig. 9a. The specific capacitance of the AC2000-FWCNT (9: 1) electrode was about twice that of the AC1000-FWCNT electrode at a scan rate of $5 \mathrm{mV} \mathrm{s}^{-1}\left(170 \mathrm{~F} \mathrm{~g}^{-1} v s .78 \mathrm{~F} \mathrm{~g}^{-1}\right)$, and four times higher at a scan rate of $100 \mathrm{mV} \mathrm{s}^{-1}\left(132 \mathrm{~F} \mathrm{~g}^{-1}\right.$ vs. $\left.32 \mathrm{~F} \mathrm{~g}^{-1}\right)$. This difference, even at low scan rates, resulted from their different SSAs. A higher SSA translates into higher EDL capacitance. ${ }^{\mathbf{4 6}}$ At low scan rate, the AC pore structure could be fully used, ${ }^{47}$ yielding the highest EDL capacitance for both electrodes. Faster scan rates caused the performance of both electrodes to decrease, but this decrease was less pronounced for the AC2000-FWCNT electrode than the AC1000-FWCNT one because of its smaller ESR.

Fig. $9 \mathrm{~b}$ and $\mathrm{c}$ shows that the magnitude of the ESRs determined from the diameter of the high-frequency semicircle in the Nyquist plots was $1.1 \Omega$ for the AC2000-FWCNT electrode and $2.4 \Omega$ for the AC1000-FWCNT electrode. At low frequencies, the AC2000-FWCNT electrode exhibited a straight vertical line parallel to the imaginary axis, typical of an ideally polarisable electrode. The line in this region of the Nyquist plot of the AC1000-FWCNT electrode inclines to the imaginary axis, and its angle indicates the diffusive resistance of the electrolyte in the electrode. ${ }^{41,48}$

For EC applications, carbon materials with high SSAs usually have high energy densities because there is more area for charge accumulation and EDL formation. Other factors such as electrical conductivity, pore size distribution, type of electrolyte and surface chemistry also play major roles in the capacitance of a material, and the relationship between specific capacitance and surface area is not linear. ${ }^{49}$ To enhance the electrical contact between AC and CNTs, the number of contact points between the FWCNTs and AC particles in the parallel circuit should be increased. This can be achieved by dispersing and separating AC particles, and binding them with FWCNTs. The number of contacts between the FWCNTs in a series circuit can also be decreased by increasing the FWCNT length. Longer FWCNTs can
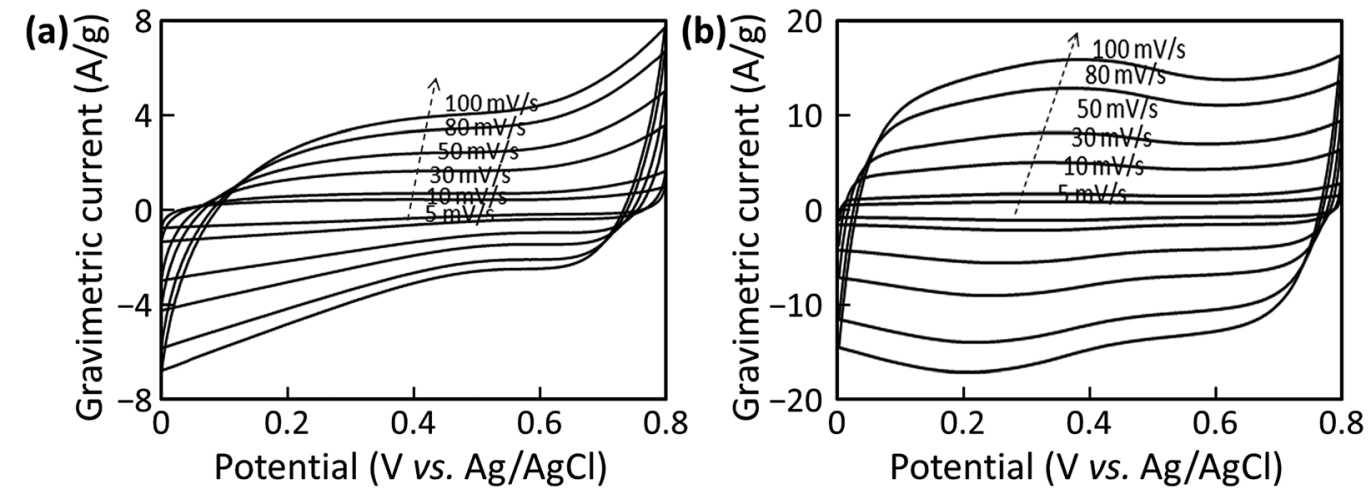

Fig. 8 CVs measured at different scan rates for the (a) AC1000-FWCNT (9:1) and (b) AC2000-FWCNT (9:1) electrodes. 

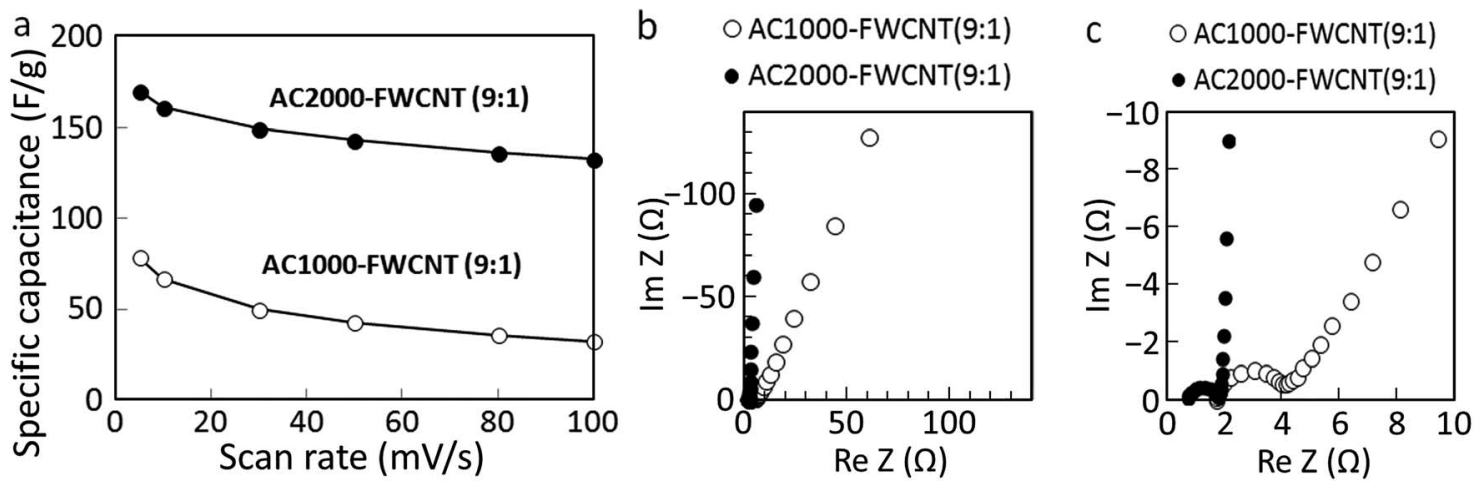

Fig. 9 (a) Rate performance determined from CV measurements of AC1000-FWCNT (9:1) and AC2000-FWCNT (9:1) hybrid electrodes. Nyquist plots for the same electrodes for the (b) entire range and (c) high-frequency range.

reduce the number of contact points in series, and compensate for the poor conductivity of the porous AC particles.

\section{Effect of FWCNT loading on electrode performance}

A higher FWCNT loading results in higher conductivity and rate performance, but lower SSA and increased cost. The effect of FWCNT loading on electrode performance was investigated, and the results are shown in Fig. 10a. ${ }^{33}$ Without FWCNTs but with $5 \mathrm{wt} \% \mathrm{AB}$ and $5 \mathrm{wt} \%$ PTFE, which are respectively conductive and binding additives commonly used in ECs, the specific capacitance of the electrode was reasonable at low scan rate $\left(148 \mathrm{~F} \mathrm{~g}^{-1}\right.$ at $\left.5 \mathrm{mV} \mathrm{s}^{-1}\right)$, but decreased sharply at high scan rates to $74 \mathrm{~F} \mathrm{~g}^{-1}$ at $100 \mathrm{mV} \mathrm{s}^{-1}$. The addition of $5 \mathrm{wt} \%$ FWCNTs in place of $\mathrm{AB}$ and PTFE caused the conductivity to increase considerably, and resulted in specific capacitance of 172 and $119 \mathrm{~F} \mathrm{~g}^{-1}$ at 5 and $100 \mathrm{mV} \mathrm{s}^{-1}$, respectively. For the electrode with $20 \mathrm{wt} \%$ FWCNTs, the decrease in specific capacitance with scan rate was less pronounced $\left(112 \mathrm{~F} \mathrm{~g}^{-1}\right.$ at $\left.100 \mathrm{mV} \mathrm{s}^{-1}\right)$, although the maximum specific capacitance decreased to $149 \mathrm{~F} \mathrm{~g}^{-1}$ at $5 \mathrm{mV} \mathrm{s}^{-1}$. A mid-point occurred for the electrode containing $10 \mathrm{wt} \%$ FWCNTs, where the performance was the highest across a wide range of scan rates $\left(170 \mathrm{~F} \mathrm{~g}^{-1}\right.$ at $5 \mathrm{mV} \mathrm{s}^{-1}$ and $132 \mathrm{~F} \mathrm{~g}^{-1}$ at
$100 \mathrm{mV} \mathrm{s}^{-1}$ ). In addition, $10 \mathrm{wt} \%$ FWCNTs is sufficiently low that its cost will not be significant. The performance of electrodes containing $\mathrm{AB}$ and PTFE as binders serves as a reference for the performance of a conventional capacitor, and clearly reveals the advantages of using a FWCNT matrix instead.

ESR of the conventional architecture ( $5 \mathrm{wt} \% \mathrm{AB}+5 \mathrm{wt} \% \mathrm{PTFE})$ and $5 \mathrm{wt} \%$ FWCNT electrodes were determined from Nyquist plots (Fig. 10b and c), revealing comparable internal resistances of 2.3 and $2.2 \Omega$, respectively. Electrodes containing 10 and $20 \mathrm{wt} \%$ FWCNTs both exhibited smaller internal resistances of $1.1 \Omega$.

\section{Comparison between the representative electrodes}

For real device applications, in addition to specific capacitance, volumetric capacitance and areal capacitance are very important. Table 3 summarizes the structure, property, and capacitance values for the representative AC-AB-PTFE, pure-SWCNT, and AC2000-FWCNT electrodes. These electrodes had mass densities of $0.35-0.50 \mathrm{~g} \mathrm{~cm}^{-3}$, which is close to the conventional AC-based electrodes $\left(\sim 0.5 \mathrm{~g} \mathrm{~cm}^{-3}\right) .{ }^{50}$ Small loading density can yield high specific capacitance values but high loading density is essential for real device (note that a current collector of 15 $\mu \mathrm{m}$-thick $\mathrm{Al}$ foil is as heavy as $4 \mathrm{mg} \mathrm{cm}^{-2}$ ). All these electrodes
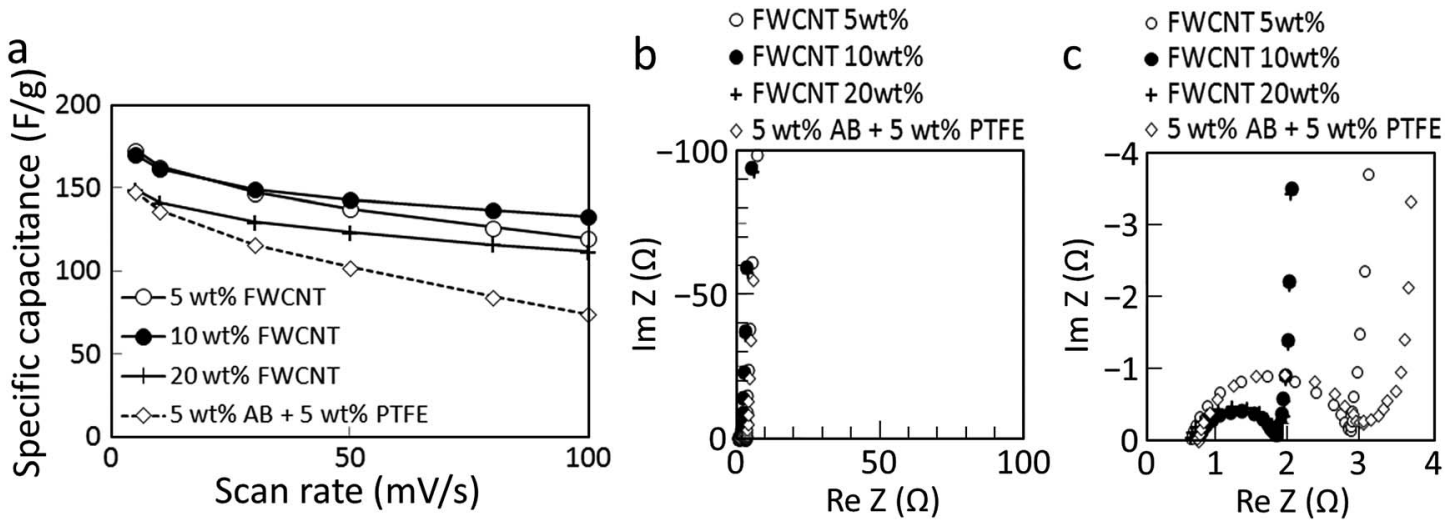

Fig. 10 (a) Rate performance determined from CV measurements for AC2000-FWCNT hybrid electrodes with different FWCNT loading. ${ }^{33}$ The performance of the conventional architecture of $90 \mathrm{wt} \%$ AC2000 with $5 \mathrm{wt} \%$ AB and $5 \mathrm{wt} \%$ PTFE is also shown. Nyquist plots for the same electrodes for the (b) whole range and (c) high-frequency range. 
Table 3 Structure and capacitance values of the representative electrodes of this work

\begin{tabular}{llll}
\hline & AC-AB-PTFE & & $\begin{array}{l}\text { AC2000-FWCNT } \\
(9: 1)(\text { EtOH })\end{array}$ \\
\hline Thickness $(\mu \mathrm{m})$ & 231 & Pure-SWCNT (SDBS) & 100 \\
Mass density $\left(\mathrm{g} \mathrm{cm}^{-3}\right)$ & 0.35 & 0.50 & 0.44 \\
Loading density $\left(\mathrm{mg} \mathrm{cm}^{-2}\right)$ & 8.2 & 5.0 & 5.3 \\
Conductivity $\left(\mathrm{S} \mathrm{cm}^{-1}\right)$ & 0.16 & 118 & 10.1 \\
Specific capacitance $\left(\mathrm{F} \mathrm{g}^{-1}\right)\left(\right.$ at $\left.5-100 \mathrm{mV} \mathrm{s}^{-1}\right)$ & $148-74$ & $55-52$ & $170-132$ \\
Volumetric capacitance $\left(\mathrm{F} \mathrm{cm}^{-3}\right)\left(\right.$ at $\left.5-100 \mathrm{mV} \mathrm{s}^{-1}\right)$ & $52-26$ & $28-26$ & $74-58$ \\
Areal capacitance $\left(\mathrm{F} \mathrm{cm}^{-2}\right)\left(\right.$ at $\left.5-100 \mathrm{mV} \mathrm{s}^{-1}\right)$ & $1.21-0.60$ & $0.28-0.26$ & $0.91-0.70$
\end{tabular}

have high loading densities of $5.0-8.2 \mathrm{~g} \mathrm{~cm}^{-3}$. The conventional AC-AB-PTFE electrode showed high specific, volumetric, and areal capacitance values at a low scan rate of $5 \mathrm{mV} \mathrm{s}^{-1}$ but inferior values at a high scan rate of $100 \mathrm{mV} \mathrm{s}^{-1}$ due to the small conductivity of $0.16 \mathrm{~S} \mathrm{~cm}^{-1}$. The pure-SWCNT electrode showed small capacitance values, which remained almost constant for different scan rates due to the high conductivity of $118 \mathrm{~S} \mathrm{~cm}^{-1}$. The AC2000-FWCNT electrode showed the best balance; high specific, volumetric, and areal capacitances at both low and high scan rates, due to the high AC content of $90 \%$ and fair conductivity of $10.1 \mathrm{~S} \mathrm{~cm}^{-1}$.

\section{Conclusions}

CNTs have been widely used to make hybrid electrodes with various capacitive particles for ECs. Because the overall performance of hybrid electrodes mainly depends on their structure, we systematically examined the materials and process conditions for hybrid electrodes using $\mathrm{AC}$ as a capacitive material and vacuum filtration processing. SDBS was a good CNT dispersant, and enhanced the conductivity of pure CNT films more than EtOH and NMP. EtOH was a poor CNT dispersant, but was better for retaining the capacitance of $\mathrm{AC}$ than $\mathrm{H}_{2} \mathrm{O}-\mathrm{SDBS}$, because of its easy removal from AC pores. SWCNTs were better suited for pure CNT electrodes than FWCNTs because of their large SSA and conductivity. Meanwhile, FWCNTs were better suited for AC-CNT hybrid electrodes because of their better dispersion in EtOH than SWCNTs. Combining FWCNTs as a conductive matrix with EtOH as a dispersant to prepare AC-CNT hybrid electrodes achieved the highest performance of the examined combinations.

The FWCNTs provided a highly conductive network that captured the AC particles in the hybrid electrodes processed in EtOH. Smaller AC particles with larger SSAs were better capacitive materials than larger particles because their interiors could be used at reasonable rates. Addition of $10 \mathrm{wt} \%$ FWCNTs to AC yielded a self-supporting hybrid electrode that exhibited the best balance of rate performance and capacitance of those investigated and recorded $170-132 \mathrm{~F} \mathrm{~g}^{-1}, 74-58 \mathrm{~F} \mathrm{~cm}^{-3}$, and $0.91-0.70 \mathrm{~F} \mathrm{~cm}^{-2}$ at $5-100 \mathrm{mV} \mathrm{s}^{-1}$ for fairly large thickness $(122 \mu \mathrm{m})$, mass density $\left(0.44 \mathrm{~g} \mathrm{~cm}^{-3}\right)$, and loading density $\left(5.3 \mathrm{mg} \mathrm{cm}^{-2}\right)$. The addition of a small proportion of CNTs to AC is practical from an economical viewpoint. Careful processing of such hybrid structures will realise further improvements in the performance of hybrid capacitor electrodes.

\section{Acknowledgements}

The authors thank Prof. Kuroda, Prof. Shimojima and $\mathrm{Mr}$ Yamamoto at Waseda University for their support with BET measurements and Kuraray Co., Ltd. for AC particles. This study was supported by a Grant-in-Aid for Scientific Research (A) (no. 25249111) from Japan Society for the Promotion of Science, Japan, and by the Advanced Low Carbon Technology Research and Development (ALCA) Program from Japan Science and Technology Agency, Japan.

\section{Notes and references}

1 P. Simon and Y. Gogotsi, Nat. Mater., 2008, 7, 845.

2 L. L. Zhang, R. Zhou and X. S. Zhao, J. Mater. Chem., 2010, 20, 5983.

3 A. Lewandowski and M. Galinski, J. Power Sources, 2007, 173, 822.

4 J. P. Zheng, P. J. Cygan and T. R. Jow, J. Electrochem. Soc., 1995, 142, 2699.

5 C.-C. Hu and T.-W. Tsou, Electrochem. Commun., 2002, 4, 105. 6 C.-C. Hu and T.-W. Tsou, Electrochim. Acta, 2002, 47, 3523.

7 Y. Honda, T. Haramoto, M. Takeshige, H. Shiozaki, T. Kitamura, K. Yoshikawa and M. Ishikawa, J. Electrochem. Soc., 2008, 155, A930.

8 C. Niu, E. K. Sichel, R. Hoch, D. Moy and H. Tennent, Appl. Phys. Lett., 1997, 70, 1480.

9 A. Izadi-Najafabadi, S. Yasuda, K. Kobashi, T. Yamada, D. N. Futaba, H. Hatori, M. Yumura, S. Iijima and K. Hata, Adv. Mater., 2010, 22, E235.

10 T. Kudo, Y. Ikeda, T. Watanabe, M. Hibino, M. Miyayama, H. Abe and K. Kajita, Solid State Ionics, 2002, 152-153, 833.

11 S. W. Lee, J. Kim, S. Chen, P. T. Hammond and Y. ShaoHorn, ACS Nano, 2010, 4, 3889.

12 R. Ma, B. Wei, C. Xu, J. Liang and D. Wu, Bull. Chem. Soc. Jpn., 2000, 73, 1813.

13 X. Qin, S. Durbach and G. T. Wu, Carbon, 2004, 42, 451.

14 Y. Wang, H. Liu, X. Sun and I. Zhitomirsky, Scr. Mater., 2009, 61, 1079.

15 Y.-T. Kim, K. Tadai and T. Mitani, J. Mater. Chem., 2005, 15, 4914. 
16 W. Lu, L. Qu, K. Henry and L. Dai, J. Power Sources, 2009, 189, 1270.

17 L. A. Girifalco, M. Hodak and R. S. Lee, Phys. Rev. B: Condens. Matter, 2000, 62, 13104.

18 T. Hertel, R. E. Walkup and P. Avouris, Phys. Rev. B: Condens. Matter, 1998, 58, 13870.

19 S. Berber, Y.-K. Kwon and D. Tománek, Phys. Rev. Lett., 2000, 84, 4613.

20 J. N. Coleman, U. Khan and Y. K. Gun'ko, Adv. Mater., 2006, 18, 689.

21 Q. Zhang, J.-Q. Huang, M.-Q. Zhao, W.-Z. Qian and F. Wei, ChemSusChem, 2011, 4, 864.

22 D. Y. Kim, H. Sugime, K. Hasegawa, T. Osawa and S. Noda, Carbon, 2011, 49, 1972.

23 Z. Chen, D. Y. Kim, K. Hasegawa, T. Osawa and S. Noda, Carbon, 2014, 80, 339.

24 D. Y. Kim, H. Sugime, K. Hasegawa, T. Osawa and S. Noda, Carbon, 2012, 50, 1538.

25 S. W. Lee, B. M. Gallant, Y. Lee, N. Yoshida, D. Y. Kim, Y. Yamada, S. Noda, A. Yamada and Y. Shao-Horn, Energy Environ. Sci., 2012, 5, 5437.

26 C. Emmenegger, P. Mauron, P. Sudan, P. Wenger, V. Hermann, R. Gallay and A. Züttel, J. Power Sources, 2003, 124, 321.

27 W. Lu, R. Hartman, L. Qu and L. Dai, J. Phys. Chem. Lett., 2011, 2, 655.

28 C. Portet, P. L. Taberna, P. Simon and E. Flahaut, J. Power Sources, 2005, 139, 371.

29 Y. Show and K. Imaizumi, Diamond Relat. Mater., 2006, 15, 2086.

30 H. Chen, J. Di, Y. Jin, M. Chen, J. Tian and Q. Li, J. Power Sources, 2013, 237, 325.

31 J. Smithyman, A. Moench, R. Liang, J. Zheng, B. Wang and C. Zhang, Appl. Phys. A, 2012, 107, 723.

32 G. Xu, C. Zheng, Q. Zhang, J. Huang, M. Zhao, J. Nie, X. Wang and F. Wei, Nano Res., 2011, 4, 870.

33 R. Quintero, D. Y. Kim, K. Hasegawa, Y. Yamada, A. Yamada and S. Noda, RSC Adv., 2014, 4, 8230.
34 W. G. Pell and B. E. Conway, J. Power Sources, 2001, 96, 57. 35 H. Tantang, J. Y. Ong, C. L. Loh, X. Dong, P. Chen, Y. Chen, X. Hu, L. P. Tan and L.-J. Li, Carbon, 2009, 47, 1867.

36 Y.-T. Kim, Y. Ito, K. Tadai, T. Mitani, U.-S. Kim, H.-S. Kim and B.-W. Cho, Appl. Phys. Lett., 2005, 87, 234106.

37 L. Lai, H. Yang, L. Wang, B. K. Teh, J. Zhong, H. Chou, L. Chen, W. Chen, Z. Shen, R. S. Ruoff and J. Lin, ACS Nano, 2012, 6, 5941.

38 S. K. Park, Q. Mahmood and H. S. Park, Nanoscale, 2013, 5, 12304.

39 E. Raymundo-Piñero, M. Cadek, M. Wachtler and F. Béguin, ChemSusChem, 2011, 4, 943.

40 Y. Wang, Z. Iqbal and S. Mitra, J. Am. Chem. Soc., 2006, 128, 95.

41 J. Shen, A. Liu, Y. Tu, G. Foo, C. Yeo, M. B. Chan-Park, R. Jiang and Y. Chen, Energy Environ. Sci., 2011, 4, 4220.

42 J. Hilding, E. A. Grulke, Z. George Zhang and F. Lockwood, J. Dispersion Sci. Technol., 2003, 24, 1.

43 A. Yu, V. Chabot and J. Zhang, Electrochemical Supercapacitors: Energy Storage Delivery Fundamentals Applications, Taylor \& Francis, 2013.

44 R. Zhang, B. Zhou, Q.-G. Guo, X.-J. Duan, X.-M. Liu, L.-C. Ling and M.-L. Jing, Materials for Renewable Energy \& Environment (ICMREE), 2011 International Conference on (vol. 1), IEEE, 2011, p. 635.

45 K.-W. Kim, M. Kuppuswamy and R. F. Savinell, J. Appl. Electrochem., 2000, 30, 543.

46 M. J. Bleda-Martínez, J. A. Maciá-Agulló, D. Lozano-Castelló, E. Morallón, D. Cazorla-Amorós and A. Linares-Solano, Carbon, 2005, 43, 2677-2684.

47 R. Kötz and M. Carlen, Electrochim. Acta, 2000, 45, 2483.

48 J. H. Jang, S. Yoon, B. H. Ka, Y.-H. Jung and S. M. Oh, J. Electrochem. Soc., 2005, 152, A1418.

49 R. Signorelli, D. C. Ku, J. G. Kassakian and J. E. Schindall, Proc. IEEE, 2009, 97, 1837.

50 F. Béguin and E. Frackowiak, Carbons for Electrochemical Energy Storage and Conversion Systems, CRC Press, 2010. 